\title{
Minimal Nonnegative Solution of Nonlinear Impulsive Differential Equations on Infinite Interval
}

\author{
Xuemei Zhang, ${ }^{1}$ Xiaozhong Yang, ${ }^{1}$ and Meiqiang Feng ${ }^{2}$ \\ ${ }^{1}$ Department of Mathematics and Physics, North China Electric Power University, Beijing 102206, China \\ ${ }^{2}$ School of Applied Science, Beijing Information Science and Technology University, Beijing 100192, China \\ Correspondence should be addressed to Xuemei Zhang, zxm74@sina.com
}

Received 20 May 2010; Accepted 19 July 2010

Academic Editor: Gennaro Infante

Copyright (c) 2011 Xuemei Zhang et al. This is an open access article distributed under the Creative Commons Attribution License, which permits unrestricted use, distribution, and reproduction in any medium, provided the original work is properly cited.

\begin{abstract}
The cone theory and monotone iterative technique are used to investigate the minimal nonnegative solution of nonlocal boundary value problems for second-order nonlinear impulsive differential equations on an infinite interval with an infinite number of impulsive times. All the existing results obtained in previous papers on nonlocal boundary value problems are under the case of the boundary conditions with no impulsive effects or the boundary conditions with impulsive effects on a finite interval with a finite number of impulsive times, so our work is new. Meanwhile, an example is worked out to demonstrate the main results.
\end{abstract}

\section{Introduction}

The theory of impulsive differential equations describes processes which experience a sudden change of their state at certain moments. Processes with such a character arise naturally and often, especially in phenomena studied in physics, chemical technology, population dynamics, biotechnology, and economics. The theory of impulsive differential equations has become an important area of investigation in the recent years and is much richer than the corresponding theory of differential equations. For an introduction of the basic theory of impulsive differential equations in $R^{n}$; see Lakshmikantham et al. [1], Bainov and Simeonov [2], and Samorlenko and Perestyuk [3] and the references therein.

Usually, we only consider the differential equation, integrodifferential equation, functional differential equations, or dynamic equations on time scales on a finite interval with a finite number of impulsive times. To identify a few, we refer the reader to [4-13] and references therein. In particular, we would like to mention some results of Guo and Liu 
[5] and Guo [6]. In [5], by using fixed-point index theory for cone mappings, Guo and Liu investigated the existence of multiple positive solutions of a boundary value problem for the following second-order impulsive differential equation:

$$
\begin{gathered}
-x^{\prime \prime}(t)=f(t, x(t)) \quad t \in J, t \neq t_{k}, k=1,2, \ldots, m, \\
\left.\Delta x\right|_{t=t_{k}}=I_{k}\left(x\left(t_{k}\right)\right), \quad k=1,2, \ldots, m, \\
a x(0)-b x^{\prime}(0)=\theta, \quad c x(1)+d x^{\prime}(1)=\theta,
\end{gathered}
$$

where $f \in C(J \times P, P), J=[0,1], P$ is a cone in the real Banach space $E, \theta$ denotes the zero element of $E, f(t, \theta)=\theta$ for $t \in J, I_{k}(\theta)=\theta, k=1,2, \ldots, m, 0<t_{1}<t_{2}<\cdots<t_{k}<\cdots<t_{m}<$ $1, a \geq 0, b \geq 0, c \geq 0, d \geq 0$ and $\delta=a c+a d+b c>0$.

In [6], by using fixed-point theory, Guo established the existence of solutions of a boundary value problem for the following second-order impulsive differential equation in a Banach space $E$ :

$$
\begin{gathered}
-x^{\prime \prime}(t)=f\left(t, x, x^{\prime}(t)\right) \quad t \in J, t \neq t_{k}, k=1,2, \ldots, m, \\
\left.\Delta x\right|_{t=t_{k}}=I_{k}\left(x\left(t_{k}\right)\right), \quad k=1,2, \ldots, m, \\
\left.\Delta x^{\prime}\right|_{t=t_{k}}=N_{k}\left(x\left(t_{k}\right), x^{\prime}\left(t_{k}\right)\right), \quad k=1,2, \ldots, m, \\
a x(0)-b x^{\prime}(0)=x_{0}, \quad c x(1)+d x^{\prime}(1)=x_{0}^{*},
\end{gathered}
$$

where $f \in C(J \times E \times E, E), J=[0,1], I_{k} \in C[E, E], N_{k} \in C[E \times E, E], x_{0}, x_{0}^{*} \in E, 0<t_{1}<t_{2}<$ $\cdots<t_{k}<\cdots<t_{m}<1$, and $p=a c+a d+b c \neq 0$.

On the other hand, the readers can also find some recent developments and applications of the case that impulse effects on a finite interval with a finite number of impulsive times to a variety of problems from Nieto and Rodríguez-López [14-16], Jankowski [17-19], Lin and Jiang [20], Ma and Sun [21], He and Yu [22], Feng and Xie [23], Yan [24], Benchohra et al. [25], and Benchohra et al. [26].

Recently, in [27], Li and Nieto obtained some new results of the case that impulse effects on an infinite interval with a finite number of impulsive times. By using a fixed-point theorem due to Avery and Peterson [28], Li and Nieto considered the existence of multiple positive solutions of the following impulsive boundary value problem on an infinite interval:

$$
\begin{aligned}
u^{\prime \prime}(t)+q(t) f(t, u) & =0, \quad \forall 0<t<\infty, t \neq t_{k}, k=1,2, \ldots, p \\
\Delta u\left(t_{k}\right) & =I_{k}\left(u\left(t_{k}\right)\right), \quad k=1,2, \ldots, p, \\
u(0) & =\sum_{i=1}^{m-2} \alpha_{i} u\left(\xi_{i}\right), \quad u^{\prime}(\infty)=0,
\end{aligned}
$$

where $f \in C([0,+\infty) \times[0,+\infty),[0,+\infty)), I_{k} \in C([0,+\infty),[0,+\infty)), u^{\prime}(\infty)=\lim _{t \rightarrow+\infty} u^{\prime}(t), 0<$ $\xi_{1}<\xi_{2}<\cdots<\xi_{m-2}<\infty, 0<t_{1}<t_{2}<\cdots<t_{p}<+\infty$, and $q \in C([0,+\infty),[0,+\infty))$. 
At the same time, we also notice that there has been increasing interest in studying nonlinear differential equation and impulsive integrodifferential equation on an infinite interval with an infinite number of impulsive times; to identify a few, we refer the reader to Guo and Liu [29], Guo [30-32], and Li and Shen [33]. It is here worth mentioning the works by Guo [31]. In [31], Guo investigated the minimal nonnegative solution of the following initial value problem for a second order nonlinear impulsive integrodifferential equation of Volterra type on an infinite interval with an infinite number of impulsive times in a Banach space $E$ :

$$
\begin{gathered}
x^{\prime \prime}=f(t, x, T x), \quad \forall t \geq 0, t \neq t_{k}, \\
\left.\Delta x\right|_{t=t_{k}}=I_{k}\left(x\left(t_{k}\right)\right), \\
\left.\Delta x^{\prime}\right|_{t=t_{k}}=N_{k}\left(x\left(t_{k}\right)\right) \quad(k=1,2, \ldots), \\
x(0)=x_{0}, \quad x^{\prime}(0)=x_{0}^{*},
\end{gathered}
$$

where $f \in C(J \times P \times P, E), I_{k}, N_{k} \in C[P, P], J=[0, \infty), x_{0}, x_{0}^{*} \in P, 0<t_{1}<\cdots<t_{k}<\cdots<$ $\cdots, t_{k} \rightarrow \infty$, as $k \rightarrow \infty, P$ is a cone of $E$.

However, the corresponding theory for nonlocal boundary value problems for impulsive differential equations on an infinite interval with an infinite number of impulsive times is not investigated till now. Now, in this paper, we will use the cone theory and monotone iterative technique to investigate the existence of minimal nonnegative solution for a class of second-order nonlinear impulsive differential equations on an infinite interval with an infinite number of impulsive times.

Consider the following boundary value problem for second-order nonlinear impulsive differential equation:

$$
\begin{gathered}
-x^{\prime \prime}(t)=f\left(t, x(t), x^{\prime}(t)\right) \quad t \in J, t \neq t_{k}, \\
\left.\Delta x\right|_{t=t_{k}}=I_{k}\left(x\left(t_{k}\right)\right), \quad k=1,2, \ldots, \\
\left.\Delta x^{\prime}\right|_{t=t_{k}}=\bar{I}_{k}\left(x\left(t_{k}\right)\right), \quad k=1,2, \ldots, \\
x(0)=\int_{0}^{\infty} g(t) x(t) d t, \quad x^{\prime}(\infty)=0,
\end{gathered}
$$

where $J=[0, \infty), f \in C\left(J \times R^{+} \times R^{+}, R^{+}\right), R^{+}=[0,+\infty), 0<t_{1}<t_{2}<\cdots<t_{k}<$ $\cdots, t_{k} \rightarrow \infty, I_{k} \in C\left[R^{+}, R^{+}\right], \bar{I}_{k} \in C\left[R^{+}, R^{+}\right], g(t) \in C\left(R^{+}, R^{+}\right)$, with $\int_{0}^{\infty} g(t) d t<1 . x^{\prime}(\infty)=$ $\lim _{t \rightarrow \infty} x^{\prime}(t) .\left.\Delta x\right|_{t=t_{k}}$ denotes the jump of $x(t)$ at $t=t_{k}$, that is,

$$
\left.\Delta x\right|_{t=t_{k}}=x\left(t_{k}^{+}\right)-x\left(t_{k}^{-}\right),
$$

where $x\left(t_{k}^{+}\right)$and $x\left(t_{k}^{-}\right)$represent the right-hand limit and left-hand limit of $x(t)$ at $t=t_{k}$, respectively. $\left.\Delta x^{\prime}\right|_{t=t_{k}}$ has a similar meaning for $x^{\prime}(t)$. 
Let

$P C[J, R]=\left\{x: x\right.$ is a map from $J$ into $R$ such that $x(t)$ is continuous at $t \neq t_{k}$, left continuous at $t=t_{k}$ and $x\left(t_{k}^{+}\right)$exist for $\left.k=1,2, \ldots\right\}$,

$P C^{1}[J, R]=\left\{x \in P C[J, R]: x^{\prime}(t)\right.$ exists and is continuous at $t \neq t_{k}$, left continuous at $t=t_{k}$ and $x^{\prime}\left(t_{k}^{+}\right)$exist for $\left.k=1,2, \ldots\right\}$.

Let $E=\left\{x \in P C^{1}[J, R]: \sup _{t \in J}(|x(t)| /(1+t))<\infty, \sup _{t \in J}\left|x^{\prime}(t)\right|<\infty\right\}$ with the norm $\|x\|=\max \left\{\|x\|_{1},\left\|x^{\prime}\right\|_{\infty}\right\}$, where

$$
\|x\|_{1}=\sup _{t \in J} \frac{|x(t)|}{1+t}, \quad\left\|x^{\prime}\right\|_{\infty}=\sup _{t \in J}\left|x^{\prime}(t)\right|
$$

Define a cone $P \subset E$ by

$$
P=\left\{x \in E: x(t) \geq 0, x^{\prime}(t) \geq 0\right\}
$$

Let $J^{\prime}=J \backslash\left\{t_{1}, t_{2}, \ldots, t_{k}, \ldots,\right\}, J_{0}=\left[0, t_{1}\right]$, and $J_{i}=\left(t_{i}, t_{i+1}\right](i=1,2,3, \ldots) . x \in E \cap$ $C^{2}\left[J^{\prime}, R\right]$ is called a nonnegative solution of (1.5), if $x(t) \geq 0, x^{\prime}(t) \geq 0$ and $x(t)$ satisfies (1.5).

If $I_{k}=0, \bar{I}_{k}=0, k=1,2, \ldots, g(t)=0$, then boundary value problem (1.5) reduces to the following two point boundary value problem:

$$
\begin{gathered}
-x^{\prime \prime}(t)=f\left(t, x(t), x^{\prime}(t)\right) \quad t \in J, \\
x(0)=0, \quad x^{\prime}(\infty)=0,
\end{gathered}
$$

which has been intensively studied; see Ma [34], Agarwal and O'Regan [35], Constantin [36], Liu [37, 38], and Yan and Liu [39] for some references along this line.

The organization of this paper is as follows. In Section 2, we provide some necessary background. In Section 3, the main result of problem (1.5) will be stated and proved. In Section 4 , we give an example to illustrate how the main results can be used in practice.

\section{Preliminaries}

To establish the existence of minimal nonnegative solution in $E$ of problem (1.5), let us list the following assumptions, which will stand throughout this paper. 
$\left(H_{1}\right)$ Suppose that $f \in C\left[J \times R^{+} \times R^{+}, R^{+}\right], I_{k} \in C\left[R^{+}, R^{+}\right], \bar{I}_{k} \in C\left[R^{+}, R^{+}\right]$, and there exist $p, q, r \in C\left(J, R^{+}\right)$and nonnegative constants $c_{k}, d_{k}, e_{k}, f_{k}$ such that

$$
\begin{gathered}
f(t, u, v) \leq p(t) u+q(t) v+r(t), \quad \forall t \in J, \text { and } \forall u, v \in R^{+}, \\
I_{k}(u) \leq c_{k} u+d_{k}, \quad \forall u \in R^{+}(k=1,2,3 \ldots), \\
\bar{I}_{k}(u) \leq e_{k} u+f_{k}, \quad \forall u \in R^{+}(k=1,2,3 \ldots), \\
p^{*}=\int_{0}^{\infty} p(t)(t+1) d t<\infty, \quad q^{*}=\int_{0}^{\infty} q(t) d t<\infty, \\
r^{*}=\int_{0}^{\infty} r(t) d t<\infty, \quad c^{*}=\sum_{k=1}^{\infty}\left(t_{k}+1\right) c_{k}<\infty, \\
d^{*}=\sum_{k=1}^{\infty} d_{k}<\infty, \quad e^{*}=\sum_{k=1}^{\infty}\left(t_{k}+1\right) e_{k}<\infty, \quad f^{*}=\sum_{k=1}^{\infty} f_{k}<\infty .
\end{gathered}
$$

$\left(H_{2}\right) f\left(t, u_{1}, v_{1}\right) \leq f\left(t, u_{2}, v_{2}\right), I_{k}\left(u_{1}\right) \leq I_{k}\left(u_{2}\right), \bar{I}_{k}\left(u_{1}\right) \leq \bar{I}_{k}\left(u_{2}\right)$, for $t \in J, u_{1} \leq u_{2}, v_{1} \leq$ $v_{2}(k=1,2,3 \ldots)$.

Lemma 2.1. Suppose that $\left(H_{1}\right)$ holds. Then for all $x \in P, \int_{0}^{\infty} f\left(t, x(t), x^{\prime}(t)\right) d t, \sum_{k=1}^{\infty} I_{k}\left(x\left(t_{k}\right)\right)$, and $\sum_{k=1}^{\infty} \bar{I}_{k}\left(x\left(t_{k}\right)\right)$ are convergent.

Proof. By $\left(H_{1}\right)$, we have

$$
\begin{gathered}
f\left(t, x(t), x^{\prime}(t)\right) \leq p(t)(t+1) \frac{x(t)}{t+1}+q(t) x^{\prime}(t)+r(t), \\
I_{k}\left(x\left(t_{k}\right)\right) \leq c_{k}\left(t_{k}+1\right) \frac{x\left(t_{k}\right)}{t_{k}+1}+d_{k}, \\
\bar{I}_{k}\left(x\left(t_{k}\right)\right) \leq e_{k}\left(t_{k}+1\right) \frac{x\left(t_{k}\right)}{t_{k}+1}+f_{k} .
\end{gathered}
$$

Thus,

$$
\begin{gathered}
\int_{0}^{\infty} f\left(s, x(s), x^{\prime}(s)\right) d s \leq p^{*}\|x\|_{1}+q^{*}\left\|x^{\prime}\right\|_{\infty}+r^{*}<\infty, \\
\sum_{k=1}^{\infty} I_{k}\left(x\left(t_{k}\right)\right) \leq c^{*}\|x\|_{1}+d^{*}<\infty \\
\sum_{k=1}^{\infty} \bar{I}_{k}\left(x\left(t_{k}\right)\right) \leq e^{*}\|x\|_{1}+f^{*}<\infty .
\end{gathered}
$$

The proof is complete. 
Lemma 2.2. Suppose that $\left(H_{1}\right)$ holds. If $0 \leq \int_{0}^{\infty} g(t) d t<1$, then $x \in E \cap C^{2}\left[J^{\prime}, R\right]$ is a solution of problem (1.5) if and only if $x \in E$ is a solution of the following impulsive integral equation:

$$
\begin{gathered}
x(t)=\int_{0}^{\infty} G(t, s) f\left(s, x(s), x^{\prime}(s)\right) d s+\sum_{k=1}^{\infty} G\left(t, t_{k}\right) \bar{I}_{k}\left(x\left(t_{k}\right)\right)+\sum_{k=1}^{\infty} G_{s}^{\prime}\left(t, t_{k}\right) I_{k}\left(x\left(t_{k}\right)\right) \\
+\frac{1}{1-\int_{0}^{\infty} g(t) d t} \int_{0}^{\infty} g(t)\left[\int_{0}^{\infty} G(t, s) f\left(s, x(s), x^{\prime}(s)\right) d s+\sum_{k=1}^{\infty} G\left(t, t_{k}\right) \bar{I}_{k}\left(x\left(t_{k}\right)\right)\right. \\
\left.+\sum_{k=1}^{\infty} G_{s}^{\prime}\left(t, t_{k}\right) I_{k}\left(x\left(t_{k}\right)\right)\right] d t, \quad \forall t \in J,
\end{gathered}
$$

where

$$
\begin{gathered}
G(t, s)= \begin{cases}t, & 0 \leq t \leq s<+\infty \\
s, & 0 \leq s \leq t<+\infty\end{cases} \\
G_{s}^{\prime}(t, s)= \begin{cases}0, & 0 \leq t \leq s<+\infty \\
1, & 0 \leq s \leq t<+\infty\end{cases}
\end{gathered}
$$

Proof. First, suppose that $x \in E \cap C^{2}\left[J^{\prime}, R\right]$ is a solution of problem (1.5). It is easy to see by integration of (1.5) that

$$
-x^{\prime}(t)+x^{\prime}(0)=\int_{0}^{t} f\left(s, x(s), x^{\prime}(s)\right) d s+\sum_{t_{k}<t} \bar{I}_{k}\left(x\left(t_{k}\right)\right)
$$

Taking limit for $t \rightarrow \infty$, by Lemma 2.1 and the boundary conditions, we have

$$
x^{\prime}(0)=\int_{0}^{\infty} f\left(s, x(s), x^{\prime}(s)\right) d s+\sum_{k=1}^{\infty} \bar{I}_{k}\left(x\left(t_{k}\right)\right) .
$$

Thus,

$$
x^{\prime}(t)=\int_{0}^{\infty} f\left(s, x(s), x^{\prime}(s)\right) d s+\sum_{k=1}^{\infty} \bar{I}_{k}\left(x\left(t_{k}\right)\right)-\int_{0}^{t} f\left(s, x(s), x^{\prime}(s)\right) d s-\sum_{t_{k}<t} \bar{I}_{k}\left(x\left(t_{k}\right)\right) .
$$


Integrating (2.8), we can get

$$
\begin{aligned}
x(t)= & x(0)+\int_{0}^{\infty} G(t, s) f\left(s, x(s), x^{\prime}(s)\right) d s+\sum_{k=1}^{\infty} G\left(t, t_{k}\right) \bar{I}_{k}\left(x\left(t_{k}\right)\right)+\sum_{k=1}^{\infty} G_{s}^{\prime}\left(t, t_{k}\right) I_{k}\left(x\left(t_{k}\right)\right) \\
= & \int_{0}^{\infty} g(t) x(t) d t+\int_{0}^{\infty} G(t, s) f\left(s, x(s), x^{\prime}(s)\right) d s \\
& +\sum_{k=1}^{\infty} G\left(t, t_{k}\right) \bar{I}_{k}\left(x\left(t_{k}\right)\right)+\sum_{k=1}^{\infty} G_{s}^{\prime}\left(t, t_{k}\right) I_{k}\left(x\left(t_{k}\right)\right) .
\end{aligned}
$$

It follows that

$$
\begin{aligned}
\int_{0}^{\infty} g(t) d t=\frac{1}{1-\int_{0}^{\infty} g(t) x(t) d t} \int_{0}^{\infty} g(t)[ & \int_{0}^{\infty} G(t, s) f\left(s, x(s), x^{\prime}(s)\right) d s \\
& \left.+\sum_{k=1}^{\infty} G\left(t, t_{k}\right) \bar{I}_{k}\left(x\left(t_{k}\right)\right)+\sum_{k=1}^{\infty} G_{s}^{\prime}\left(t, t_{k}\right) \mathrm{I}_{k}\left(x\left(t_{k}\right)\right)\right] d t .
\end{aligned}
$$

So we have (2.4).

Conversely, suppose that $x \in E$ is a solution of (2.4). Evidently,

$$
\left.\Delta x\right|_{t=t_{k}}=I_{k}\left(x\left(t_{k}\right)\right), \quad(k=1,2, \ldots,) .
$$

Direct differentiation of (2.4) implies, for $t \neq t_{k}$,

$$
\begin{gathered}
x^{\prime}(t)=\int_{t}^{\infty} f\left(s, x(s), x^{\prime}(s)\right) d s+\sum_{t_{k} \geq t} \bar{I}_{k}\left(x\left(t_{k}\right)\right), \\
\left.\Delta x^{\prime}\right|_{t=t_{k}}=\bar{I}_{k}\left(x\left(t_{k}\right)\right), \quad(k=1,2, \ldots,), \\
x^{\prime \prime}(t)=-f\left(t, x(t), x^{\prime}(t)\right) .
\end{gathered}
$$

So $x \in C^{2}\left[J^{\prime}, R\right]$. It is easy to verify that $x(0)=\int_{0}^{\infty} g(t) x(t) d t, x^{\prime}(\infty)=0$. The proof of Lemma 2.2 is complete.

Define an operator $T: E \rightarrow E$,

$$
\begin{gathered}
(T x)(t)=\int_{0}^{\infty} G(t, s) f\left(s, x(s), x^{\prime}(s)\right) d s+\sum_{k=1}^{\infty} G\left(t, t_{k}\right) \bar{I}_{k}\left(x\left(t_{k}\right)\right)+\sum_{k=1}^{\infty} G_{s}^{\prime}\left(t, t_{k}\right) I_{k}\left(x\left(t_{k}\right)\right) \\
+\frac{1}{1-\int_{0}^{\infty} g(t) d t} \int_{0}^{\infty} g(t)\left[\int_{0}^{\infty} G(t, s) f\left(s, x(s), x^{\prime}(s)\right) d s+\sum_{k=1}^{\infty} G\left(t, t_{k}\right) \bar{I}_{k}\left(x\left(t_{k}\right)\right)\right. \\
\left.+\sum_{k=1}^{\infty} G_{s}^{\prime}\left(t, t_{k}\right) I_{k}\left(x\left(t_{k}\right)\right)\right] d t, \quad \forall t \in J .
\end{gathered}
$$


Lemma 2.3. Assume that $\left(H_{1}\right)$ and $\left(H_{2}\right)$ hold. Then operator T maps $P$ into $P$, and

$$
\|T x\| \leq \beta+\alpha\|x\|, \quad \forall x \in P,
$$

where

$$
\alpha=\frac{2-\int_{0}^{\infty} g(t) d t}{1-\int_{0}^{\infty} g(t) d t}\left(p^{*}+q^{*}+c^{*}+e^{*}\right), \quad \beta=\frac{2-\int_{0}^{\infty} g(t) d t}{1-\int_{0}^{\infty} g(t) d t}\left(r^{*}+f^{*}+d^{*}\right) .
$$

Moreover, for $x, y \in P$ with $x(t) \leq y(t), x^{\prime}(t) \leq y^{\prime}(t)$, for all $t \in J^{\prime}$, one has

$$
(T x)(t) \leq(T y)(t), \quad(T x)^{\prime}(t) \leq(T y)^{\prime}(t), \quad \forall t \in J^{\prime}
$$

Proof. Let $x \in P$. From the definition of $T$ and $\left(H_{1}\right)$, we can obtain that $T$ is an operator from $P$ into $P$, and

$$
\begin{aligned}
& \frac{|(T x)(t)|}{1+t} \\
\leq & \int_{0}^{\infty}\left|f\left(s, x(s), x^{\prime}(s)\right)\right| d s+\sum_{k=1}^{\infty}\left|\bar{I}_{k}\left(x\left(t_{k}\right)\right)\right| \\
& +\sum_{k=1}^{\infty}\left|I_{k}\left(x\left(t_{k}\right)\right)\right|+\frac{1}{1-\int_{0}^{\infty} g(t) d t}\left(\int_{0}^{\infty}\left|f\left(s, x(s), x^{\prime}(s)\right)\right| d s+\sum_{k=1}^{\infty}\left|\bar{I}_{k}\left(x\left(t_{k}\right)\right)\right|+\sum_{k=1}^{\infty}\left|I_{k}\left(x\left(t_{k}\right)\right)\right|\right) \\
\leq & \frac{2-\int_{0}^{\infty} g(t) d t}{1-\int_{0}^{\infty} g(t) d t}\left(p^{*}+q^{*}+c^{*}+e^{*}\right)\|x\|+\frac{2-\int_{0}^{\infty} g(t) d t}{1-\int_{0}^{\infty} g(t) d t}\left(r^{*}+f^{*}+d^{*}\right) \\
= & \alpha\|x\|+\beta, \quad \forall t \in J .
\end{aligned}
$$

Direct differentiation of (2.13) implies, for $t \neq t_{k}$,

$$
(T x)^{\prime}(t)=\int_{t}^{\infty} f\left(s, x(s), x^{\prime}(s)\right) d s+\sum_{t_{k} \geq t} \bar{I}_{k}\left(x\left(t_{k}\right)\right) .
$$

Thus we have $\left|(T x)^{\prime}(t)\right| \leq \int_{0}^{\infty}\left|f\left(s, x(s), x^{\prime}(s)\right)\right| d s+\sum_{k=1}^{\infty}\left|\bar{I}_{k}\left(x\left(t_{k}\right)\right)\right| \leq \alpha\|x\|+\beta$, for all $t \in J^{\prime}$. It follows that (2.14) is satisfied. Equation (2.16) is easily obtained by $\left(H_{2}\right)$. 


\section{Main Result}

In this section, we establish the existence of a minimal nonnegative solution for problem (1.5).

Theorem 3.1. Let conditions $\left(H_{1}\right)-\left(H_{2}\right)$ be satisfied. Suppose further that

$$
\alpha=\frac{2-\int_{0}^{\infty} g(t) d t}{1-\int_{0}^{\infty} g(t) d t}\left(p^{*}+q^{*}+c^{*}+e^{*}\right)<1 .
$$

Then problem (1.5) has the minimal nonnegative solution $\bar{x}$ with $\|\bar{x}\| \leq \beta /(1-\alpha)$, where $\beta$ is defined as in Lemma 2.3. Here, the meaning of minimal nonnegative solution is that if $x$ is an arbitrary nonnegative solution of (1.5), then $x(t) \geq \bar{x}(t), x^{\prime}(t) \geq \overline{x^{\prime}}(t)$, for all $t \in J^{\prime}$. Moreover, if we let $x_{0}(t)=0, x_{n}(t)=\left(T x_{n-1}\right)(t)$, for all $t \in J(n=1,2, \ldots)$, then $x_{n} \subset P$ with

$$
\begin{gathered}
0=x_{0}(t) \leq x_{1}(t) \leq \cdots \leq x_{n}(t) \leq \cdots \leq \bar{x}(t), \quad \forall t \in J, \\
0=x_{0}^{\prime}(t) \leq x_{1}^{\prime}(t) \leq \cdots \leq x_{n}^{\prime}(t) \leq \cdots \leq \overline{x^{\prime}}(t), \quad \forall t \in J^{\prime},
\end{gathered}
$$

and $\left\{x_{n}(t)\right\}$ and $\left\{x_{n}^{\prime}(t)\right\}$ converge uniformly to $\bar{x}(t)$ and $\overline{x^{\prime}}(t)$ on $J_{i},(i=0,1,2, \ldots)$, respectively.

Proof. By Lemma 2.3 and the definition of operator $T$, we have $x_{n} \subset P$, and

$$
\begin{gathered}
\left\|x_{n}\right\| \leq \beta+\alpha\left\|x_{n-1}\right\| \quad(n=1,2,3, \ldots), \\
0=x_{0}(t) \leq x_{1}(t) \leq \cdots \leq x_{n}(t) \leq \cdots, \quad \forall t \in J \\
0=x_{0}^{\prime}(t) \leq x_{1}^{\prime}(t) \leq \cdots \leq x_{n}^{\prime}(t) \leq \cdots, \quad \forall t \in J^{\prime} .
\end{gathered}
$$

By (3.3), we have

$$
\left\|x_{n}\right\| \leq \beta+\alpha \beta+\alpha^{2} \beta+\cdots+\alpha^{n-1} \beta=\frac{\beta\left(1-\alpha^{n}\right)}{1-\alpha} \leq \frac{\beta}{1-\alpha}, \quad(n=1,2 \ldots) .
$$

From (3.4), (3.5), and (3.6), we know that $\lim _{n \rightarrow \infty} x_{n}(t)$ and $\lim _{n \rightarrow \infty} x_{n}^{\prime}(t)$ exist. Suppose that

$$
\lim _{n \rightarrow \infty} x_{n}(t)=\bar{x}(t), \quad \lim _{n \rightarrow \infty} x_{n}^{\prime}(t)=y(t), \quad \forall t \in J^{\prime} .
$$


By the definition of $x_{n}(t)$, we have

$$
\begin{gathered}
x_{n}^{\prime}(t)=\int_{t}^{\infty} f\left(s, x_{n-1}(s), x_{n-1}^{\prime}(s)\right) d s+\sum_{t_{k} \geq t} \bar{I}_{k}\left(x_{n}\left(t_{k}\right)\right), \quad \forall t \in J^{\prime},(n=1,2, \ldots), \\
x_{n}^{\prime \prime}(t)=-f\left(t, x_{n-1}(t), x_{n-1}^{\prime}(t)\right), \quad \forall t \in J^{\prime},(n=1,2, \ldots) .
\end{gathered}
$$

From (3.6), we obtain

$$
\frac{\left|x_{n}(t)\right|}{t+1} \leq \frac{\beta}{1-\alpha}, \quad\left|x_{n}^{\prime}(t)\right| \leq \frac{\beta}{1-\alpha}, \quad \forall t \in J^{\prime},(n=1,2, \ldots)
$$

It follows that $\left\{x_{n}(t)\right\}$ is equicontinuous on every $J_{i} \quad(i=0,1,2, \ldots)$. Combining this with Ascoli-Arzela theorem and diagonal process, there exists a subsequence which converges uniformly to $\bar{x}(t)$ on $J_{i}(i=0,1,2, \ldots)$. Which together with (3.4) imply that $\left\{x_{n}(t)\right\}$ converges uniformly to $\bar{x}(t)$ on $J_{i}(i=0,1,2, \ldots)$, and $\bar{x} \in P C[J, R],\|\bar{x}\|_{1} \leq \beta /(1-\alpha)$. On the other hand, by $\left(H_{1}\right),(3.6)$, and $(3.9)$, we have

$$
\begin{aligned}
\left|x_{n}^{\prime \prime}(t)\right| & \leq p(t)(t+1)\left\|x_{n-1}\right\|_{1}+q(t)\left\|x_{n-1}^{\prime}\right\|_{\infty}+r(t) \\
& \leq p(t)(t+1) \frac{\beta}{1-\alpha}+q(t) \frac{\beta}{1-\alpha}+r(t)=s(t) \in C\left(J, R^{+}\right), \quad \forall t \in J^{\prime} \quad(n=1,2, \ldots) .
\end{aligned}
$$

Since $s(t)$ is bounded on $[0, M]$ (M is a finite positive number), $\left\{x^{\prime}{ }_{n}(t)\right\}$ is equicontinuous on every $J_{i}, i=1,2, \ldots$ Combining this with Ascoli-Arzela theorem and diagonal process, there exists a subsequence which converges uniformly to $y(t)$ on $J_{i}(i=0,1,2, \ldots)$, which together with (3.5) imply that $\left\{x_{n}^{\prime}(t)\right\}$ converges uniformly to $y(t)$ on $J_{i}(i=0,1,2, \ldots)$, and $y \in P C[J, R],\|y\|_{\infty} \leq \beta /(1-\alpha)$. From above, we know that $\overline{x^{\prime}}(t)$ exists and $\overline{x^{\prime}}(t)=$ $y(t)$, for all $t \in J^{\prime}$. It follows that $\bar{x} \in P$ and

$$
\|\bar{x}\| \leq \frac{\beta}{1-\alpha}
$$

Now we prove that $\bar{x}(t)=(T \bar{x})(t)$.

By the continuity of $f$ and the uniform convergence of $x_{n}(t), x_{n}^{\prime}(t)$, we know that

$$
f\left(s, x_{n}(s), x_{n}^{\prime}(s)\right) \longrightarrow f\left(s, \bar{x}(s), \overline{x^{\prime}}(s)\right), \quad n \longrightarrow \infty, \forall t \in J^{\prime}
$$

On the other hand, by $\left(H_{1}\right)$ and (3.6) and (3.12), we have

$$
\begin{aligned}
& \left|f\left(s, x_{n}(s), x_{n}^{\prime}(s)\right)-f\left(s, \bar{x}(s), \overline{x^{\prime}}(s)\right)\right| \\
& \quad \leq 2(p(s)(s+1)+q(s)) \frac{\beta}{1-\alpha}+2 r(s)=z(s) \in L\left[J, R^{+}\right] \quad(n=1,2, \ldots) .
\end{aligned}
$$


Combining this with the dominated convergence theorem, we have

$$
\begin{array}{cl}
\lim _{n \rightarrow \infty} \int_{t}^{\infty} f\left(s, x_{n}(s), x_{n}^{\prime}(s)\right) d s=\int_{t}^{\infty} f\left(s, \bar{x}(s), \overline{x^{\prime}}(s)\right) d s, \quad \forall t \in J, \\
\lim _{n \rightarrow \infty} \int_{0}^{t} f\left(s, x_{n}(s), x_{n}^{\prime}(s)\right) d s=\int_{0}^{t} f\left(s, \bar{x}(s), \overline{x^{\prime}}(s)\right) d s, \quad \forall t \in J .
\end{array}
$$

Moreover, we can see that

$$
\begin{aligned}
\lim _{n \rightarrow \infty} \sum_{0<t_{k}<t} I_{k}\left(x_{n}\left(t_{k}\right)\right) & =\sum_{0<t_{k}<t} I_{k}\left(\bar{x}\left(t_{k}\right)\right), \\
\lim _{n \rightarrow \infty} \sum_{0<t_{k}<t} \bar{I}_{k}\left(x_{n}\left(t_{k}\right)\right) & =\sum_{0<t_{k}<t} \bar{I}_{k}\left(\bar{x}\left(t_{k}\right)\right), \\
\lim _{n \rightarrow \infty} \sum_{t_{k} \geq t} I_{k}\left(x_{n}\left(t_{k}\right)\right) & =\sum_{t_{k} \geq t} I_{k}\left(\bar{x}\left(t_{k}\right)\right), \\
\lim _{n \rightarrow \infty} \sum_{t_{k} \geq t} \bar{I}_{k}\left(x_{n}\left(t_{k}\right)\right) & =\sum_{t_{k} \geq t} \bar{I}_{k}\left(\bar{x}\left(t_{k}\right)\right) .
\end{aligned}
$$

Now taking limits from two sides of $x_{n}(t)=\left(T x_{n-1}\right)(t)$ and using (3.15)-(3.16), we have

$$
\begin{aligned}
& \bar{x}(t)=\int_{0}^{\infty} G(t, s) f\left(s, \bar{x}(s), \overline{x^{\prime}}(s)\right) d s+\sum_{k=1}^{\infty} G\left(t, t_{k}\right) \bar{I}_{k}\left(\bar{x}\left(t_{k}\right)\right)+\sum_{k=1}^{\infty} G_{s}^{\prime}\left(t, t_{k}\right) I_{k}\left(\bar{x}\left(t_{k}\right)\right) \\
&+\frac{1}{1-\int_{0}^{\infty} g(t) d t} \int_{0}^{\infty} g(t)\left[\int_{0}^{\infty} G(t, s) f\left(s, \bar{x}(s), \overline{x^{\prime}}(s)\right) d s\right. \\
&\left.+\sum_{k=1}^{\infty} G\left(t, t_{k}\right) \bar{I}_{k}\left(\bar{x}\left(t_{k}\right)\right)+\sum_{k=1}^{\infty} G_{s}^{\prime}\left(t, t_{k}\right) I_{k}\left(\bar{x}\left(t_{k}\right)\right)\right] d t, \quad \forall t \in J .
\end{aligned}
$$

By Lemma 2.2, $\bar{x}(t)$ is a nonnegative solution of (1.5).

Suppose that $x \in P \cap C^{2}\left[J^{\prime}, R\right]$ is an arbitrary nonnegative solution of (1.5). Then $x(t)=(T x)(t)$. It is clear that $x(t) \geq 0, x^{\prime}(t) \geq 0, \forall t \in J^{\prime}$. Suppose that $x(t) \geq x_{n-1}(t), x^{\prime}(t) \geq$ $x_{n-1}^{\prime}(t)$, for all $t \in J^{\prime}$. By (2.16) we have $(T x)(t) \geq\left(T x_{n-1}\right)(t),(T x)^{\prime}(t) \geq\left(T x_{n-1}\right)^{\prime}(t)$, for all $t \in$ $J^{\prime}$. This means that $x(t) \geq x_{n}(t), x^{\prime}(t) \geq x_{n}^{\prime}(t)$, for all $t \in J^{\prime}(n=1,2, \ldots)$. Taking limit, we have $x(t) \geq \bar{x}(t), x^{\prime}(t) \geq \overline{x^{\prime}}(t)$, for all $t \in J^{\prime}$. The proof of Theorem 3.1 is complete. 


\section{Example}

To illustrate how our main results can be used in practice, we present an example.

Example 4.1. Consider the following boundary value problem of second-order impulsive differential equation on infinite interval

$$
\begin{gathered}
-x^{\prime \prime}=\frac{1}{100}(t+1)^{-9 / 4}\left(1+x+x^{\prime}\right)^{2 / 3}, \quad t \in J, t \neq k, \\
\left.\Delta x\right|_{t=k}=\frac{1}{8^{k}}(x(k)+1)^{1 / 2} \quad(k=1,2, \ldots), \\
\left.\Delta x\right|_{t=k}=\frac{1}{10^{k}}(x(k)+1)^{1 / 2} \quad(k=1,2, \ldots), \\
x(0)=\int_{0}^{\infty} \frac{1}{2} e^{-t} x(t) d t, \quad x^{\prime}(\infty)=0,
\end{gathered}
$$

where

$$
\begin{gathered}
f(t, x, y)=\frac{1}{100}(t+1)^{-9 / 4}(1+x+y)^{2 / 3}, \\
I_{k}\left(x\left(t_{k}\right)\right)=\frac{1}{8^{k}}(x(k)+1)^{1 / 2}, \quad k=1,2, \ldots, \\
\bar{I}_{k}\left(x\left(t_{k}\right)\right)=\frac{1}{10^{k}}(x(k)+1)^{1 / 2}, \quad k=1,2, \ldots, \\
g(t)=\frac{1}{2} e^{-t} .
\end{gathered}
$$

Evidently, $x(t) \equiv 0$ is not the solution of (4.1).

\section{Conclusion}

Problem (4.1) has minimal positive solution.

Proof. It is clear that $\int_{0}^{\infty}(1 / 2) e^{-t} d t<1$ and $\left(H_{2}\right)$ is satisfied.

By the inequality $(1+x)^{\gamma} \leq 1+\gamma x$, for all $0 \leq x<\infty, 0<\gamma<1$, we see that

$$
\begin{gathered}
f(t, x, y) \leq \frac{1}{100}(t+1)^{-9 / 4}\left(1+\frac{2}{3} x+\frac{2}{3} y\right), \\
I_{k}(x) \leq \frac{1}{8^{k}}\left(1+\frac{1}{2} x\right), \quad \bar{I}_{k}(x) \leq \frac{1}{10^{k}}\left(1+\frac{1}{2} x\right), \quad k=1,2, \ldots .
\end{gathered}
$$


Let

$$
\begin{gathered}
p(t)=\frac{1}{150}(t+1)^{-9 / 4}, \quad q(t)=\frac{1}{150}(t+1)^{-9 / 4}, \quad r(t)=\frac{1}{100}(t+1)^{-9 / 4}, \\
c_{k}=\frac{1}{2 \times 8^{k}}, \quad d_{k}=\frac{1}{8^{k}}, \quad e_{k}=\frac{1}{2 \times 10^{k}}, \quad f_{k}=\frac{1}{10^{k}} .
\end{gathered}
$$

Then, we easily obtain that

$$
\begin{gathered}
\int_{0}^{\infty} p(t)(1+t) d t=\frac{4}{150}, \quad \int_{0}^{\infty} q(t) d t=\frac{4}{750}, \quad \int_{0}^{\infty} r(t) d t=\frac{2}{250}, \\
\sum_{k=1}^{\infty}\left(t_{k}+1\right) c_{k}=\frac{15}{98}, \quad \sum_{k=1}^{\infty} d_{k}=\frac{1}{7}, \quad \sum_{k=1}^{\infty}\left(t_{k}+1\right) e_{k}=\frac{19}{162}, \quad \sum_{k=1}^{\infty} f_{k}=\frac{1}{9} .
\end{gathered}
$$

Thus, $\left(H_{1}\right)$ is satisfied and $\alpha=150001 / 165375<1$. By Theorem 3.1, it follows that problem (4.1) has a minimal positive solution.

\section{Acknowledgments}

This work is supported by the National Natural Science Foundation of China (10771065), the Natural Sciences Foundation of Hebei Province (A2007001027), the Funding Project for Academic Human Resources Development in Institutions of Higher Learning Under the Jurisdiction of Beijing Municipality (PHR201008430), the Scientific Research Common Program of Beijing Municipal Commission of Education(KM201010772018), the 2010 level of scientific research of improving project (5028123900), and Beijing Municipal Education Commission(71D0911003). The authors thank the referee for his/her careful reading of the paper and useful suggestions.

\section{References}

[1] V. Lakshmikantham, D. D. Baĭnov, and P. S. Simeonov, Theory of Impulsive Differential Equations, vol. 6 of Series in Modern Applied Mathematics, World Scientific, Teaneck, NJ, USA, 1989.

[2] D. D. Baĭnov and P. S. Simeonov, Systems with Impulse Effect: Stability, Theory and Application, Ellis Horwood Series: Mathematics and Its Applications, Ellis Horwood, Chichester, UK, 1989.

[3] A. M. Samoǔlenko and N. A. Perestyuk, Impulsive Differential Equations, vol. 14 of World Scientific Series on Nonlinear Science. Series A: Monographs and Treatises, World Scientific, River Edge, NJ, USA, 1995.

[4] D. Guo, "Multiple positive solutions of impulsive nonlinear Fredholm integral equations and applications," Journal of Mathematical Analysis and Applications, vol. 173, no. 1, pp. 318-324, 1993.

[5] D. Guo and X. Liu, "Multiple positive solutions of boundary-value problems for impulsive differential equations," Nonlinear Analysis: Theory, Methods E Applications, vol. 25, no. 4, pp. 327-337, 1995.

[6] D. Guo, "Existence of solutions of boundary value problems for nonlinear second order impulsive differential equations in Banach spaces," Journal of Mathematical Analysis and Applications, vol. 181, no. 2, pp. 407-421, 1994.

[7] D. Guo, "Periodic boundary value problems for second order impulsive integro-differential equations in Banach spaces," Nonlinear Analysis: Theory, Methods E Applications, vol. 28, no. 6, pp. 983-997, 1997.

[8] X. Liu, "Monotone iterative technique for impulsive differential equations in a Banach space," Journal of Mathematical and Physical Sciences, vol. 24, no. 3, pp. 183-191, 1990. 
[9] A. S. Vatsala and Y. Sun, "Periodic boundary value problems of impulsive differential equations," Applicable Analysis, vol. 44, no. 3-4, pp. 145-158, 1992.

[10] J. J. Nieto, "Basic theory for nonresonance impulsive periodic problems of first order," Journal of Mathematical Analysis and Applications, vol. 205, no. 2, pp. 423-433, 1997.

[11] Z. He and W. Ge, "Periodic boundary value problem for first order impulsive delay differential equations," Applied Mathematics and Computation, vol. 104, no. 1, pp. 51-63, 1999.

[12] M. Benchohra, J. Henderson, S. K. Ntouyas, and A. Ouahab, "Impulsive functional differential equations with variable times," Computers E Mathematics with Applications, vol. 47, no. 10-11, pp. 16591665, 2004.

[13] M. Benchohra, S. K. Ntouyas, and A. Ouahab, "Existence results for second order boundary value problem of impulsive dynamic equations on time scales," Journal of Mathematical Analysis and Applications, vol. 296, no. 1, pp. 65-73, 2004.

[14] J. J. Nieto and R. Rodríguez-López, "New comparison results for impulsive integro-differential equations and applications," Journal of Mathematical Analysis and Applications, vol. 328, no. 2, pp. 13431368, 2007.

[15] J. J. Nieto and R. Rodríguez-López, "Monotone method for first-order functional differential equations," Computers \& Mathematics with Applications, vol. 52, no. 3-4, pp. 471-484, 2006.

[16] J. J. Nieto and R. Rodríguez-López, "Periodic boundary value problem for non-Lipschitzian impulsive functional differential equations," Journal of Mathematical Analysis and Applications, vol. 318, no. 2, pp. 593-610, 2006.

[17] T. Jankowski, "Positive solutions of three-point boundary value problems for second order impulsive differential equations with advanced arguments," Applied Mathematics and Computation, vol. 197, no. 1, pp. 179-189, 2008.

[18] T. Jankowski, "Positive solutions to second order four-point boundary value problems for impulsive differential equations," Applied Mathematics and Computation, vol. 202, no. 2, pp. 550-561, 2008.

[19] T. Jankowski, "Existence of solutions for second order impulsive differential equations with deviating arguments," Nonlinear Analysis: Theory, Methods \& Applications, vol. 67, no. 6, pp. 1764-1774, 2007.

[20] X. Lin and D. Jiang, "Multiple positive solutions of Dirichlet boundary value problems for second order impulsive differential equations," Journal of Mathematical Analysis and Applications, vol. 321, no. 2, pp. 501-514, 2006.

[21] Y. Ma and J. Sun, "Stability criteria for impulsive systems on time scales," Journal of Computational and Applied Mathematics, vol. 213, no. 2, pp. 400-407, 2008.

[22] Z. He and J. Yu, "Periodic boundary value problem for first-order impulsive functional differential equations," Journal of Computational and Applied Mathematics, vol. 138, no. 2, pp. 205-217, 2002.

[23] M. Feng and D. Xie, "Multiple positive solutions of multi-point boundary value problem for secondorder impulsive differential equations," Journal of Computational and Applied Mathematics, vol. 223, no. 1, pp. 438-448, 2009.

[24] J. Yan, "Existence of positive periodic solutions of impulsive functional differential equations with two parameters," Journal of Mathematical Analysis and Applications, vol. 327, no. 2, pp. 854-868, 2007.

[25] M. Benchohra, S. K. Ntouyas, and A. Ouahab, "Extremal solutions of second order impulsive dynamic equations on time scales," Journal of Mathematical Analysis and Applications, vol. 324, no. 1, pp. 425-434, 2006.

[26] M. Benchohra, J. Henderson, and S. K. Ntouyas, Impulsive Differential Equations and Inclusions, Hindawi, New York, NY, USA, 2006.

[27] J. Li and J. J. Nieto, "Existence of positive solutions for multipoint boundary value problem on the half-line with impulses," Boundary Value Problems, vol. 2009, Article ID 834158, 12 pages, 2009.

[28] R. I. Avery and A. C. Peterson, "Three positive fixed points of nonlinear operators on ordered Banach spaces," Computers \& Mathematics with Applications, vol. 42, no. 3-5, pp. 313-322, 2001.

[29] D. Guo and X. Z. Liu, "Impulsive integro-differential equations on unbounded domain in a Banach space," Nonlinear Studies, vol. 3, no. 1, pp. 49-57, 1996.

[30] D. Guo, "Boundary value problems for impulsive integro-differential equations on unbounded domains in a Banach space," Applied Mathematics and Computation, vol. 99, no. 1, pp. 1-15, 1999.

[31] D. Guo, "Second order impulsive integro-differential equations on unbounded domains in Banach spaces," Nonlinear Analysis: Theory, Methods E Applications, vol. 35, no. 4, pp. 413-423, 1999.

[32] D. Guo, "Multiple positive solutions for first order nonlinear impulsive integro-differential equations in a Banach space," Applied Mathematics and Computation, vol. 143, no. 2-3, pp. 233-249, 2003.

[33] J. Li and J. Shen, "Existence of positive solution for second-order impulsive boundary value problems on infinity intervals," Boundary Value Problems, vol. 2006, Article ID 14594, 11 pages, 2006. 
[34] R. Ma, "Existence of positive solutions for second-order boundary value problems on infinity intervals," Applied Mathematics Letters, vol. 16, no. 1, pp. 33-39, 2003.

[35] R. P. Agarwal and D. O'Regan, "Boundary value problems of nonsingular type on the semi-infinite interval," The Tohoku Mathematical Journal, vol. 51, no. 3, pp. 391-397, 1999.

[36] A. Constantin, "On an infinite interval boundary value problem," Annali di Matematica Pura ed Applicata. Serie Quarta, vol. 176, pp. 379-394, 1999.

[37] Y. Liu, "Existence and unboundedness of positive solutions for singular boundary value problems on half-line," Applied Mathematics and Computation, vol. 144, no. 2-3, pp. 543-556, 2003.

[38] Y. Liu, "Boundary value problems for second order differential equations on unbounded domains in a Banach space," Applied Mathematics and Computation, vol. 135, no. 2-3, pp. 569-583, 2003.

[39] B. Yan and Y. Liu, "Unbounded solutions of the singular boundary value problems for second order differential equations on the half-line," Applied Mathematics and Computation, vol. 147, no. 3, pp. 629$644,2004$. 